\title{
CORRESPONDENCE
}

\begin{abstract}
We welcome letters to the Editor concerning articles which have recently been published. Such letters will be subject to the usual stages of selection and editing; where appropriate the authors of the original article will be offered the opportunity to reply.

Letters should normally be under $\mathbf{5 0 0}$ words in length, double-spaced throughout, signed by all authors and fully referenced. The edited version will be returned for approval before publication.
\end{abstract}

\section{PERONEUS LONGUS TENDON CALCIFICATION}

Sir,

After reading the interesting report by Cox and Paterson in your March issue (73-B:342) we were surprised that no mention was made of the os peroneum. Among us, we have seen six similar cases three of which were reported (Thompson and Patterson 1989). They had almost identical radiographs to the one presented by Cox and Patterson. The operative findings in our patients were fracture of the os peroneum and/or attrition of the peroneus longus tendon at the cuboid tunnel.

In retrospect, is it possible that their case is in fact an affliction of the os peroneum and not 'acute calcific tendinitis'?

MARK J. GEPPERT, MD MARK SOBEL, MD

FRANCESCA M. THOMPSON, MD

The Hospital for Special Surgery,

535 East 70th Street,

New York

NY 10021, USA.

Cox D, Paterson FWN. Acute calcific tendinitis of peroneus longus J Bone Joint Surg [Br] 1991 ;73-B:342.

Thompson FM, Patterson AH. Rupture of the peroneus longus tendon: report of three cases. J Bone Joint Surg [Am] 1989; 71-A :293-5.

\section{CONDENSING OSTEITIS OF THE CLAVICLE}

Sir,

We write in response to the article in your May 1990 issue by Jones et al (72-B:464-7) entitled 'Condensing osteitis of the clavicle: does it exist?'.

Based on our personal experience and a review of the literature we believe that the condition most certainly exists. It is a rare disorder seen predominantly in adult women and produces a characteristic radiographic appearance of focal sclerosis of the inferomedial end of the clavicle. Histologically, there is an increase in the amount and thickness of cancellous bone with no evidence of inflammation (Brower, Sweet and Keats 1974; Cone et al 1983; Franquet et al 1985). It appears to be related to mechanical stress

(C) 1992 British Editorial Society of Bone and Joint Surgery $0301-620 X / 92 / 1332 \$ 2.00$

J Bone Joint Surg [ Br] 1992; 74-B: 163-5. and may be identical to the lesion described as aseptic necrosis by Friedrich (1924).

Jones et al have described a completely separate lesion that is best characterised as a form of chronic recurrent multifocal osteomyelitis (CRMO), an inflammatory process of unknown aetiology that occurs primarily in children and adolescents. In this condition the radiological lesion is initially lytic and, with healing, assumes a sclerotic, expansile appearance. It involves the middle two-thirds of the clavicle, usually sparing the medial end (Eftekhari et al 1989). Histological examination shows an inflammatory process identical to that seen in the two patients described by Jones et al (Bjorksten and Boquist 1980).

CRMO is typically multifocal at presentation, but Eftekhari et al (1989) have described two children with metachronous involvement of the clavicle and femur, with typical radiographic and histological findings. In their patients, the clavicular lesions were followed by lesions in the femur, seven months and eight years later, respectively. The term 'inflammatory metachronous hyperostosis' was used to describe these findings.

Appell et al (1983) described inflammatory lesions of the mid-clavicle in seven children, four of whom had no other bone involvement. Unfortunately, they used the term 'condensing osteitis of the clavicle in children' to describe lesions that were probably also a form of CRMO.

We believe that CRMO is a fascinating clinical entity and agree with Brown and Wilkinson (1988) that "the full spectrum is still being realised as more cases are seen". This spectrum appears to include both monostotic and metachronous forms. Condensing osteitis of the clavicle is a separate, non-inflammatory process that should not be confused with CRMO or related inflammatory lesions.

ROGER KERR, MD Assistant Professor of Radiology

DONALD RESNICK, MD Professor of Radiology

University of Southern California Medical Center, Los Angeles, CA 90033, USA.

Appell RG, Oppermann HC, Becker W, et al. Condensing osteitis of the clavicle in childhood: a rare sclerotic bone lesion. Review of literature and report of seven patients. Pediatr Radiol 1983; 13:301-6.

Bjorksten BR, Boquist L. Histopathological aspects of chronic recurrent multifocal osteomyelitis. J Bone Joint Surg [Br] 1980; 62-B :376-80.

Brower AC, Sweet DE, Keats TE. Condensing osteitis of the clavicle: a new entity. $A J R$ 1974; $121: 17-21$. 